\title{
Ensino de Botânica no Ensino Fundamental: estudando o pólen por meio de multimodos ${ }^{1}$
}

\author{
Carin Stanski ${ }^{2}$, Cynthia Fernandes Pinto Luz ${ }^{3,6}$, Adriana Ribeiro Ferreira Rodrigues ${ }^{4} \mathrm{e}$ \\ Melissa Koch Fernandes de Souza Nogueira ${ }^{5}$
}

Recebido: 22.04.2015; aceito: 21.09.2015

\begin{abstract}
Botanical teaching at the Elementary School: studying the pollen through multimodes). The objective of this study is to investigate the use of multi-modal representation as a didactic strategy to facilitate the significant learning of seventh-grade elementary school students about the pollen theme, using conceptual maps in a evaluation. Students have developed conceptual maps a priori and a posteriori classes with multi-modal representation. We verified that the multi-modal representation provides a significant learning about botany contents and concept maps can be used as the evaluation tool. Keywords: Botany, conceptual maps, significative learning
\end{abstract}

RESUMO - (Ensino de Botânica no Ensino Fundamental: estudando o pólen por meio de multimodos). O presente estudo teve como objetivo investigar o uso de multimodos de representação como estratégia didática para facilitar a aprendizagem significativa de alunos da sétima série do Ensino Fundamental referente ao tema pólen, utilizando mapas conceituais como avaliação. Os alunos elaboraram mapas conceituais à priori e à posteriori as aulas com multimodos de representação. Verificamos que os multimodos de representação propiciam uma aprendizagem significativa sobre conteúdos de botânica e que os mapas conceituais podem ser utilizados como avaliação.

Palavras-chave: Aprendizagem significativa, botânica, mapas conceituais

\section{Introdução}

O ensino de Ciências não se resume somente à apresentação de definições de conceitos científicos. As definições são um dos objetivos do processo de ensino, aquilo que se pretende que o aluno compreenda ao longo de suas investigações, da mesma forma que conceitos, procedimentos e atitudes também são aprendidos (Brasil 1997).

Segundo Carvalho (1997), “é no Ensino Fundamental que os alunos tomam contato pela primeira vez com o Ensino de Ciências e com certos conceitos científicos, sendo assim, muito da aprendizagem subsequente de Ciências depende desse primeiro contato".
Para o ensino de Ciências é necessária a construção de uma estrutura geral de determinada área, que favoreça a aprendizagem significativa do conhecimento historicamente acumulado e a formação de uma concepção da Ciência, suas relações com a Tecnologia e com a Sociedade (Brasil 1997).

$\mathrm{O}$ ensino de Botânica nas séries do Ensino Fundamental vem sendo marcado no Brasil por uma série de problemas, entre os mais evidentes, está a falta de interesse dos alunos pelo conteúdo, que segundo Silva (2008) ocorre devido a dificuldade de se estabelecer uma relação direta do ser humano com as plantas.

Silva (2008) considera que o ensino da Botânica desenvolvido nos dias atuais, em sua grande maioria,

1. Parte de Trabalho de Conclusão de Curso do primeiro Autor

2. Universidade Estadual de Ponta Grossa. Departamento de Biologia Geral, Laboratório de Palinologia. Av. General Carlos Cavalcanti, 4.748, 84030-900 Ponta Grossa, Paraná, Brasil

3. Instituto de Botânica, Núcleo de Pesquisa em Palinologia, Av. Miguel Estéfano, 3687, Água Funda, 04301-012 São Paulo, São Paulo, Brasil

4. Universidade Estadual de Londrina., Rodovia Celso Garcia Cid - PR 445, Km 380, 86057-970 Londrina, PR, Brasil

5. Universidade Estadual de Ponta Grossa, Departamento de Biologia Geral, Laboratório de Palinologia. Av. General Carlos Cavalcanti, 4.748, 84030-900 Ponta Grossa, Paraná, Brasil

6. Autor para correspondência: cyluz@yahoo.com.br 
é feito por meio de listas de nomes científicos e de palavras totalmente isoladas da realidade, usadas para definir conceitos que possivelmente nem ao menos podem ser compreendidos pelos alunos e pelos professores. Somando-se ao fato de que os livros didáticos possuem conteúdos teóricos específicos e complexos, cada vez mais distantes da realidade de alunos e professores.

As dificuldades em se ensinar e, consequentemente, em se aprender Botânica, tornam a "cegueira botânica" mais evidente, que segundo Wandersee \& Schussler (2001) refere-se à falta de habilidade apresentada para a percepção das plantas no ambiente natural, diminuindo a capacidade de reconhecimento da importância destas para a biosfera como um todo.

Desse modo, a aquisição do conhecimento em Botânica é prejudicada não somente pela falta de estímulo em se observar e interagir com as plantas, como também pela precariedade de equipamentos, métodos e tecnologias que possam ajudar no aprendizado (Arruda \& Laburú 1996, Ceccantini 2006).

A maneira de se trabalhar um conteúdo possibilita que os alunos tragam seu cotidiano para a sala de aula, sendo assim, o uso de multimodos de representação constitui-se como uma tentativa de tornar os tópicos mais concretos e interessantes para o ensino, com a finalidade de melhoria da qualidade da aprendizagem (Zompero \& Laburú 2010).

Para realmente ser significativa, a aprendizagem deve ser contínua e de descobertas, o que leva interesse aos alunos e não uma aula rotineira e mecânica que causa distanciamento do assunto. Na procura por uma melhor aprendizagem, a metodologia multimodos apresenta variadas formas de abordar o conteúdo específico e o apresentam de diferentes maneiras aos alunos por meio de imagens, músicas, jogos, cartazes, etc.

Pesquisas recentes como a de Zompero \& Laburú (2010), defendem a ideia de que uma metodologia diferente no ensino que utilize os multimodos de representação melhora os resultados referentes ao aprendizado dos alunos e, que esta, vem ganhando espaço nas discussões e nas práticas educacionais, trazendo resultados positivos em relação à apreensão e assimilação do conteúdo.

Prain \& Waldrip (2006) destacam que os multimodos empregam diferentes linguagens, vários tipos de representação que são fundamentais para que os estudantes desenvolvam uma compreensão dos diversos modos de representar um determinado conteúdo (descritivas, figurativas, sinestésicas), sem que se tornem dependentes de um modo particular ligado a um ponto específico.

Quando utilizamos diversos tipos de representação, ou seja, uma representação múltipla, todas as nuances de determinado conceito serão transmitidas através dos dois canais, o que potencializa a capacidade dessa transmissão por um lado e facilita a possibilidade de recuperação da informação por outro lado (Tavares 2004, 2005).

Laburú \& Silva (2011) discutem que, para estimular o modo representacional, as experiências devem ser observadas de forma imperativa para o ensino das Ciências, não apenas retratando a natureza epistemológica do conhecimento científico, mas carregando uma característica pedagógica que em combinação com outros modos e formas representacionais, venha a complementar e aprimorar a formação do pensamento científico. Um multimodo que envolva formas de retratar um assunto na forma de experimentos é a aula prática, que, de acordo com Laburú \& Silva (2011), é uma forma sinestésica de representação.

Para Lemke (1998) a Ciência não fala apenas do mundo na linguagem das palavras, e em muitos casos, simplesmente não pode fazê-lo. A linguagem natural da Ciência é uma integração sinérgica de palavras, diagramas, figuras, gráficos, mapas, equações, tabelas, gráficos e outras formas de expressão visual e matemática. Nessa mesma lógica pode-se pensar que o ensino de Ciências também precisa lançar mão das diferentes linguagens para ensinar.

Para que ocorra a compreensão da teoria Freire (1997) destaca que é necessário experienciá-la. Deste modo, a realização de experimentos (aulas práticas) em Ciências, representa um excelente mecanismo para que o aluno relacione a teoria à prática.

Ainda segundo Moreira et al. (2000) é por meio de práticas em sala de aula que se observa com frequência, por exemplo, em avaliações que alunos ao invés de escrever, geralmente sugerem fazer um desenho explicando a resposta através de gestos ou relacionando conceitos a um tema central o que é conhecido como Mapa Conceitual.

Segundo Moreira (1986) os Mapas Conceituais são diagramas que indicam relação entre conceitos e estes procuram ser integrados em diferentes "dimensões", que seriam as formas pelas quais os vários conceitos estão ligados a determinado objeto central. Analisando 
o conteúdo previamente, os Mapas Conceituais vêm sendo utilizados por professores como uma forma didática de quantificar o conhecimento prévio e posterior dos alunos sobre um determinado assunto. Deste modo, as múltiplas representações podem ser um auxílio didático no ensino de Ciências e uma proposta pedagógica alternativa para complementar o processo de ensino-aprendizagem, contribuindo assim para uma aprendizagem significativa.

Segundo Moreira et al. (1997) a aprendizagem significativa é o processo através do qual uma nova informação (um novo conhecimento) se relaciona de maneira não arbitrária e substantiva (não-literal) à estrutura cognitiva do aprendiz. Para Ausubel (1963 apud Moreira 1997) a aprendizagem significativa é o mecanismo humano, por excelência, para adquirir e armazenar a vasta quantidade de ideias e informações representadas em qualquer campo de conhecimento. De acordo com Moreira et al. (2000), para que uma aprendizagem significativa aconteça em relação a um determinado assunto são necessárias três circunstâncias: o material utilizado como apoio que deve abranger o conteúdo de maneira lógica; a existência na estrutura cognitiva do aprendiz de conhecimento organizado e que este, possa ser relacionado com o novo conteúdo e, por fim, a vontade e disposição do aprendiz de relacionar o novo conhecimento com aquele já adquirido.

O presente trabalho tem como objetivo investigar se os multimodos de representação propiciam a aprendizagem significativa de estudantes da sétima série (oitavo ano) do Ensino Fundamental sobre conteúdos de Botânica, utilizando mapas conceituais como forma de avaliação.

\section{Material e métodos}

A metodologia aplicada na pesquisa realizada foi de caráter empírico experimental qualitativo, que é caracterizada pela intervenção do professor/ pesquisador na realidade do aluno e cuja avaliação faz uso de instrumentos de coleta, que recolhem dos registros. Nesse tipo de metodologia, as técnicas utilizadas para obtenção de dados são a entrevista, o questionário, opiniões, testes com questões abertas.

A técnica de análise atribuída aos dados foi do tipo Análise de Conteúdo Categorial. Segundo Gohn (1984) neste tipo de análise, as categorias constituem os elementos do sistema que servem de estrutura ao conhecimento científico, orientam o pensamento no sentido da procura de solução de novos problemas científicos e constituem o instrumento básico de produção de conhecimentos.

A investigação envolveu, inicialmente, 35 alunos estudantes matriculados na sétima série (oitavo ano) do Ensino Fundamental que cursavam a disciplina de Ciências no ano letivo de 2012, no Colégio Estadual Professor João Ricardo Von Borell da rede pública de ensino, que está localizado na zona urbana da cidade de Ponta Grossa no Estado do Paraná (Brasil).

O primeiro instrumento de pesquisa utilizado antes do início das aulas foi papel e lápis para a confecção de um mapa conceitual, com a finalidade de abordar os conhecimentos prévios sobre o assunto grãos de pólen. Estes conhecimentos são significativos para os estudantes, pois são aprendidos em seu contexto cultural e familiar, muitas vezes são aceitos como verdades absolutas. Neste caso, os grãos de pólen são encontrados no mel, este está diretamente relacionado com nossa alimentação. Durante as aulas foi citado que a ciência que estuda os grãos de pólen no mel é denominada de Melissopalinologia.

O desenvolvimento do estudo de grãos de pólen se deu por meio de intervenções que foram realizadas em quatro (4) aulas de quarenta e cinco (45) minutos. A estratégia didática utilizada incluiu a aplicação de Mapas Conceituais (na fase pré-instrucional e no final das quatro aulas) e a utilização de multimodos de representação.

O primeiro mapa conceitual cujo tema central "pólen" foi denominado de Mapa Conceitual I (priori), construído antes das aulas, e o segundo mapa conceitual, também com o tema central "pólen", foi denominado de Mapa Conceitual II (posteriori).

De acordo com Prain \& Waldrip (2006), foram utilizadas nas atividades desenvolvidas em sala de aula os seguintes modos de representação: modo gráfico e visual, escrito, $3 \mathrm{D}$ e verbal. O modo gráfico e visual no desenvolvimento das aulas era composto por desenhos explicativos, imagens de grãos de pólen, que foram fotografados em Microscopia Eletrônica de Varredura, pois o mesmo é uma estrutura microscópica de difícil visualização a olho nu, com exceção de algumas espécies como Curcubita sp. (abóbora), espécie conhecida e consumida na região.

O modo escrito foi abordado nas aulas através de explicações do conteúdo com esquemas em quadro negro e giz, juntamente com a construção de mapas conceituais pelos alunos e a resolução de um questionário semiaberto. Já o modo 3D contou com peças florais como de Hibiscus sp., que apesar de ser 
uma espécie ornamental favorece a visualização das partes florais, além se ser uma flor vistosa. Também foram utilizadas lâminas de microscopia (preparadas em laboratório) contendo amostras de mel com grãos de pólen, como os da espécie Eugenia uniflora que é conhecida popularmente na região como "pitanga", que é muito visitada por abelhas na coleta de néctar para a produção do mel. Ainda foi utilizada lupa para a melhor identificação das estruturas de difícil visualização a olho nu, referentes à morfologia floral de material coletado a fresco para a aula. Todos os tipos de modos eram utilizados em sala de aula associados ao modo verbal com explicações orais durante as atividades.

Considerando que alguns modos de representação podem favorecer mais o aprendizado do que outros, privilegiando as diferentes características dos alunos nas suas distintas formas de aprender. As atividades desenvolvidas durante as aulas incluíram a identificação de peças florais de Hibiscus sp., identificação de grãos de pólen em uma lâmina contendo uma solução a base de mel (com grãos de pólen do gênero Eugenia) e suas diferentes morfologias, além de discutir a importância dos grãos de pólen para o ser humano e animais.

Ao final do desenvolvimento das atividades, os alunos foram orientados a elaborar um novo Mapa Conceitual no qual deveriam incluir o que aprenderam ao final das quatro aulas.

Para encerrar a coleta de dados, aplicou-se um questionário semiaberto após duas semanas de aulas, no qual os alunos demarcaram e justificaram qual o tipo de modo de representação foi o mais eficiente e favoreceu a melhor compreensão e assimilação do conteúdo. Esse questionário constituiu-se de duas questões: sendo a primeira objetiva, com quatro opções baseadas nos multimodos utilizados em sala de aula e, a segunda, uma questão descritiva, na qual o aluno justificou a escolha da opção da questão anterior.

A análise dos dados coletados constituiu-se na abordagem, comparações e discussões dos Mapas Conceituais, tais como quantidade de termos apresentados, estrutura e organização desses termos, relações conceituais e tipologias de conteúdo manifestadas pelos estudantes antes e depois do desenvolvimento das atividades.

\section{Resultados e Discussão}

Analisando os mapas conceituais, foi possível verificar uma grande diferença quantitativa entre os
Mapas I e II. O Mapa Conceitual I (priori) (figura 1) possui em média a metade do número de termos em comparação com Mapa Conceitual II (posteriori) (figura 2), destacando-se que ambos os mapas foram construídos pelo mesmo aluno.

Com a ampliação no número de termos, pode-se verificar que a estrutura cognitiva dos alunos passou por um processo de reorganização, ou seja, após o término das aulas, mais informações são agregadas ao tema central pólen, que são denominadas de subsunçores. De acordo com Moreira (2005) são aspectos relevantes da estrutura cognitiva que servem de ancoradouro para uma nova informação.

A maioria dos mapas construídos pelos alunos possuem estrutura e certa organização, apesar de não apresentarem palavras de ligação entre os termos, são mapas que possuem coerência. Isso pode ser observado no Mapa Conceitual II (figura 2), onde o aluno nomeia os grãos pólen como um "pó", pois é desta forma que ele observa na natureza, e liga o "pó" ao termo "alergia", que em algumas pessoas é causada pelo pólen.

Isso reafirma a ideia proposta por Zompero \& Laburú (2010) de que o trabalho com multimodos de representação em sala de aula mostra-se consistente com uma aprendizagem significativa, já que ao utilizar diferentes formas de representação o sujeito atribui significados e estabelece relações entre símbolos, palavras, objetos e conceitos.

A aprendizagem significativa é a interação de um novo conhecimento e um já existente, em que ambos se modificam (Moreira, 2005), deste modo, a cada aula os alunos foram atribuindo significados às novas informações, como no caso da "alergia" que é causada geralmente na primavera por um "pó", neste caso, "pólen". Quando os alunos relacionam o conteúdo novo com a estrutura cognitiva, ou seja, o aluno atribui os novos conhecimentos aprendidos a significados pessoais, podemos dizer que ocorreu uma aprendizagem significativa. Quando não ocorre esta relação, a aprendizagem é mecânica e não significativa.

Como sabemos que a aprendizagem não foi mecânica? Durante as aulas os alunos fizeram perguntas que relacionavam o conteúdo com o seu cotidiano, por exemplo, a formação de frutos e sementes, se é possível ter frutos sem que ocorra a polinização, e de que forma esta pode ocorrer (quem é o polinizador?). Aprenderam que, de modo geral, as flores mais vistosas, coloridas e que possuam algum tipo de odor, são as que atraem 
mais as abelhas, pássaros e insetos, e estes realizam o transporte do grão de pólen de uma flor a outra, e que as flores menos vistosas possuem sua polinização realizada geralmente pelo vento.

Observamos que muitos termos e conceitos se destacam nos mapas conceituais. Foram citados no Mapa Conceitual I os seguintes termos: abelha, borboletas, colmeia, flor, fruto, jardim, mel, natureza, néctar, nova planta, pássaros, pó, pólen, polinização, reprodução, semente, vida. No mapa conceitual II, os termos que apareceram são: abelha, alergia, alimento, alimentação das abelhas, beija-flor, borboleta, colmeia, doce, evita doenças, fecundação, flor, formiga, fruto, geléia real, melissopalinologia, mercado financeiro, monofloral, natureza, néctar, nova planta, pó, pólen, polifloral, polinizadores, polinização, reprodução, semente, urso, vida. Alguns termos do mapa conceitual priori repetem no mapa conceitual posteriori, mas verificamos que essa repetição no segundo mapa conceitual é mais estruturada e possuem mais ligações com outros termos, o que sugere que os alunos atribuíram significados a estes. Alguns termos aparecem somente no segundo mapa, como Melissopalinologia, que apesar de não ser estudado no ensino médio e no ensino superior por se tratar de um termo específico, ele foi citado nas aulas. Em alguns mapas, melissopalinologia aparece vinculada a pólen e mel, o que sugere que os alunos fizeram uma relação de que se trata do estudo do pólen presente no mel.

Entre os termos que mais apareceram nos mapas conceituais, em um mapa específico, foram citados

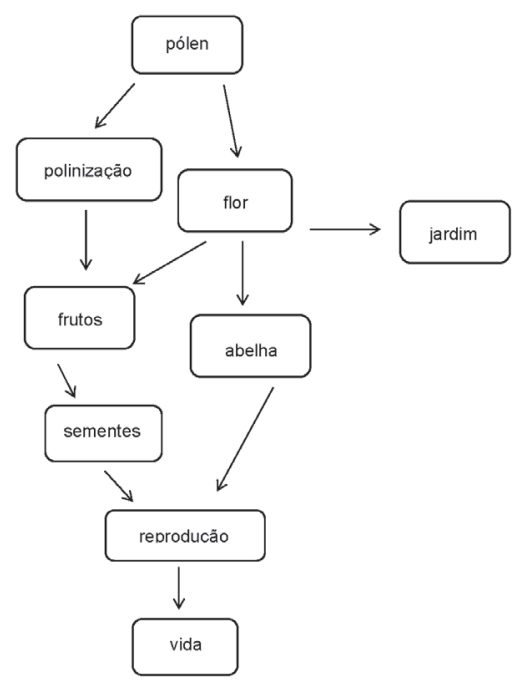

Figura 1. Exemplo de Mapa Conceitual I (priori).

Figure 1. Example of Conceptual Map I (priori). urso e formiga que estavam relacionados ao mel. Com relação ao urso, sabemos que esse animal não ocorre em nosso país, e que muito menos um aluno viu um urso se alimentando de mel. Neste caso, estas informações são obtidas nos desenhos animados, que também interferem na aprendizagem. Já no caso da formiga, foram citadas porque se alimentam de mel que é doce. Estes termos foram esclarecidos pelo aluno que elaborou um mapa conceitual.

Por fim, analisamos os questionários aplicados, no qual verificamos qual dos métodos utilizados nas aulas, segundo a opinião dos alunos, foi o mais eficiente para a melhor compreensão do conteúdo. A relação dos multimodos utilizados e a frequência baseada nas respostas obtidas dos alunos através dos questionários foram avaliadas através da porcentagem de aceitação de determinado método multimodo de ensino. De acordo com as respostas expressadas nos questionários, quadro e giz apresentaram $11 \%$ de aceitação dos alunos, seguindo-se 15\% em relação às imagens, $33 \%$ às peças florais e $41 \%$ à observação do material na lupa, sendo este último, portanto, o método mais "legal" segundo os alunos para o entendimento do assunto. Por se tratar de uma intervenção, verificamos que nesta escola, não eram utilizados lupas e microscópios nas aulas de Botânica.

Nas aulas que foram utilizados recursos didáticos como imagens, lupas, microscópios, flores, foi observado que os alunos consideraram as aulas "diferentes" e, verificamos que aulas "diferentes" atraem a atenção dos alunos. Portanto, a aula que

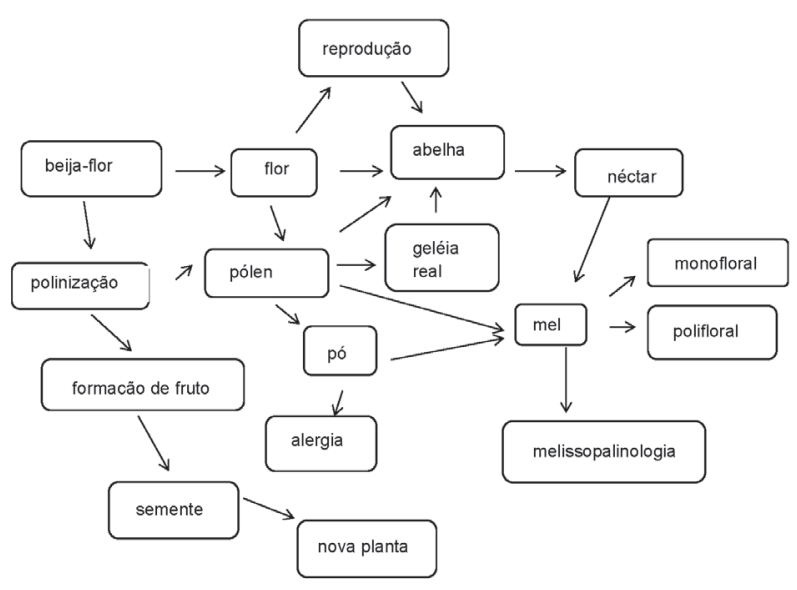

Figura 2. Exemplo de Mapa Conceitual II (posteriori).

Figure 2. Example of Conceptual Map II (posteriori). 
Tabela 1. Exemplos de justificativas positivas dos alunos referentes à escolha de determinado multimodo.

Table 1. Examples of positive justification from students concerning the choice of a particular multimode.

\begin{tabular}{|c|c|c|}
\hline Aluno & Multimodo escolhido & Justificativa \\
\hline Aluno 1 & Observação na lupa & "Porque aprendo com mais clareza." \\
\hline Aluno 3 & Observação na lupa & $\begin{array}{l}\text { "Porque podemos ver as partes da flor melhor, a aula fica } \\
\text { mais divertida e não fica monótona." }\end{array}$ \\
\hline Aluno 6 & Observação da lupa & $\begin{array}{l}\text { "É mais legal e divertido, uma coisa diferente, com isso } \\
\text { aprendo mais rápido e melhor." }\end{array}$ \\
\hline Aluno 13 & Quadro e giz & "É melhor porque a professora coloca o nome das coisas." \\
\hline Aluno 14 & Imagens & "As imagens no microscópio são mais detalhadas." \\
\hline Aluno 8 & Observação na lupa & "Deu para ver tudo mais próximo e com detalhes." \\
\hline Aluno 9 & $\begin{array}{c}\text { Imagens } \\
\text { Observação na lupa }\end{array}$ & $\begin{array}{l}\text { "É melhor para entender." } \\
\text { "É bom para ver mais especificamente." }\end{array}$ \\
\hline Aluno 12 & $\begin{array}{l}\text { Observação na lupa } \\
\text { Observação de flores }\end{array}$ & $\begin{array}{l}\text { "Porque podemos melhor observar os mínimos detalhes da } \\
\text { flor." } \\
\text { "É interessante porque podemos tocar nela e aprender mais } \\
\text { detalhadamente cada parte." }\end{array}$ \\
\hline
\end{tabular}

é cansativa e monótona, chamada de "chata" pelos alunos, causa dispersão e pouca aprendizagem. Quando ocorre a interação aluno-conteúdo-professor, a aula torna-se objetiva e clara, os alunos estabelecem uma conexão entre o conteúdo novo com o cognitivo, e deste modo gerando a aprendizagem significativa, mas para que isso ocorra precisa de recursos que tornem a aula interativa.

Felder \& Silverman (1988), baseando-se em pesquisa de outros autores, formularam um modelo de estilos de aprendizagem com dimensões que seriam relevantes para melhorar a aprendizagem em relação à educação científica. São cinco dimensões de estilos de aprendizagem: visual/verbal, sensorial/ intuitivo, indutivo/dedutivo, ativo/reflexivo, e sequencial/global. Essas dimensões trabalham a forma da captação de informações pelos estudantes, ou seja, qual seria o melhor modo de se aplicar uma aula levando-se em consideração o entendimento do conteúdo pelos alunos.

Segundo Senra et al. (2012), estudantes "visuais" obtêm informação preferencialmente a partir de imagens figurativas, diagramas, gráficos e esquemas, enquanto os "verbais" têm mais facilidade em fixar a informação através de palavras escritas e faladas. Por meio das respostas do questionário foi possível observar que a maioria dos alunos pode ser identificada como estudantes "visuais", de acordo com o expresso nas justificativas, após terem escolhido o melhor multimodo de representação, onde especificaram o porquê da escolha.
A tabela 1 consiste em algumas das justificativas apresentadas pelos alunos mediante a escolha de um dos multimodos utilizados nas aulas, sendo que por meio deste, ocorreu o melhor entendimento em relação ao conteúdo explorado nas aulas.

Ao analisar as justificativas dos alunos nota-se um resultado que pode ser considerado positivo e importante, porque os alunos relataram que têm maior facilidade em aprender mediante multimodos de representação.

A aprendizagem foi significativa, pois os alunos atribuíram significados aos termos, e caracterizamos como um processo dinâmico e o conhecimento ainda está em construção. Deste modo, não devemos levar em consideração somente o aumento no número e diversificação de termos quando comparamos o Mapa Conceitual I e o Mapa Conceitual II, e sim a relação que os alunos estabelecem dos significados aprendidos com o cotidiano.

\section{Considerações Finais}

A presente pesquisa se propôs a investigar o uso de multimodos de representações como estratégia didática para facilitar a aprendizagem significativa de alunos da sétima série (oitavo ano) do ensino fundamental referente ao tema pólen.

Consideramos que a utilização de multimodos de representações para aprendizagem significativa na sétima série sobre pólen apresenta relevantes contribuições para o ensino de ciências. 
Quanto maior o interesse do aluno nos conteúdos abordados em sala de aula, ou seja, aulas interativas com multimodos que abordam os conteúdos botânicos deixando-os mais atraentes e interessantes, maior será a aprendizagem significativa, pois há uma relação do assunto apreendido em sala de aula com o seu dia a dia, desta forma construindo novos significados.

Verificamos que os alunos participantes da pesquisa já possuíam conhecimentos em sua estrutura cognitiva prévia, justificando os termos no Mapa Conceitual I antes das aulas com multimodos. Esses conhecimentos prévios são significativos para os alunos, pois são aprendidos sob seu contexto familiar, escolar e cultural. Após as aulas com multimodos ocorreu uma reorganização cognitiva do conteúdo.

Os mapas conceituais à priori (Mapa Conceitual I) e posteriori (Mapa Conceitual II) possuem muitas semelhanças com relação á reorganização cognitiva. Verificamos que também ocorrem incoerências na elaboração destes mapas, como a falta de palavras de ligação, uma desordem na hierarquização de alguns conceitos. Contudo, não existem mapas conceituais corretos.

Como forma de avaliação, os mapas conceituais são muito subjetivos, então os alunos devem apresentar o seu mapa, não importa se está correto ou não, ou se possui muitos termos, o importante é se o mapa dá evidencias de que o aluno está aprendendo significativamente o conteúdo.

\section{Agradecimentos}

Ao Laboratório de Botânica da Universidade Estadual de Ponta Grossa (UEPG), Paraná. Ao Colégio Estadual Professor João Ricardo Von Borell, pelo uso das instalações, realização das aulas e coleta de dados.

\section{Literatura citada}

Arruda, S.M. \& Laburú, C.E. 1996. Considerações sobre a função do experimento no ensino de Ciências. Pesquisa em Ensino de Ciências e Matemática 5: 14-24.

Ausubel, D.P. 1963. The psychology of meaningful verbal learning. New York, Grune and Stratton.

Carvalho, A.M.P. 1997. Ciências no Ensino Fundamental. Caderno de Pesquisa 101: 152-168.

Ceccantini, G. 2006. Os tecidos vegetais têm três dimensões. Revista Brasileira de Botânica 29: 335-337.

Felder, R.M. \& Silverman, L.K. 1988. Learning and teaching styles in engineering education. Eng. Education. 78: 674-681.

Freire, P. 1997. Pedagogia da autonomia. Rio de Janeiro, Editora Paz e Terra.
Gohn, M.G.M. 1984. A Pesquisa das Ciências Sociais: Considerações Metodológicas. In: C.R. Brandão, Pesquisa Participante e Educação. Cadernos CEDES 12.

Laburú, C.E. \& Silva, O.H.M. 2011. Multimodos e múltiplas representações: fundamentos e perspectivas semióticas para a aprendizagem de conceitos científicos. Investigações em Ensino de Ciências 16: 7-33.

Lemke, J.L. 1998. Teaching all the languages of science: words, symbols, images and actions. Brooklyn College, City University of New York. Disponível em http:// academic. brooklyn. cuny. ed/education/jlemke/ (acesso em 06-XI-2014).

Moreira, M.A. 1986. Mapas Conceituais, Caderno Catarinense de Ensino de Física. 3: 17-25.

Moreira, M.A. 2005. Mapas Conceituais e Aprendizagem Significativa. Revista Chilena de Educação Científica 4: 38-44.

Moreira, M. A., Caballero, M. C. \& Rodríguez, M. L. (orgs.). 1997. Actas del Encuentro Internacional sobre el Aprendizaje Significativo. Burgos, España. pp. 19-44.

Novak, J.D., Moreira, M.A, Valadares, J.A., Cachapuz, A.F., Praia, J.F., Martínez, R. D., Montero, Y.H. \& Pedrosa, M.E. 2000. Teoria da Aprendizagem Significativa: Contributos do III Encontro Internacional sobre Aprendizagem Significativa, Peniche. Disponível em http://www.mlrg.org/memberpublications/ LivroPeniche2000.pdf (acesso em 30-VI-2014).

Prain, V. \& Waldrip, B. 2006. An exploratory study of teachers' and students' use of multi-modal representations of concepts in primary science. International Journal of Science Education, Abingdon, 28: 1843-1866.

Secretaria de Educação Fundamental. 1997. Parâmetros curriculares nacionais: ciências naturais. Ensino de primeira à quarta série.

Senra, M.C.S., Lima, G.F.C.A. \& Silva, F.W.O. 2012. A relação entre os estilos de aprendizagem de Richard Felder e os tipos psicológicos de Carl Jung. Disponível em http://www.senept.cefetmg.br/galerias/Arquivos senept/anais/terca_tema1/TerxaTema1Artigo21.pdf (acesso em 27-VIII-2014).

Silva, P.G.P. 2008. O ensino da botânica no nível fundamental: um enfoque nos procedimentos. Tese de Doutorado, Universidade Estadual Paulista, Faculdade de Ciências, Bauru.

Tavares, R. 2004. Aprendizagem Significativa. Revista Conceitos 10: 55-60.

Tavares, R. 2005. Animações interativas e mapas conceituais. XVI Simpósio Nacional de Ensino de Física, Rio de janeiro, Rio de Janeiro.

Wandersee, J.H. \& Schussler, E.E. Towards a theory of plant blindness. Plant Science Bulletin, v. 47, n. 1, pp. 2-9, 2001.

Zompero, F.A. \& Laburú, C.E. 2010. As relações entre aprendizagem significativa e representações multimodais. Revista Ensaio 12: 31-40. 